O conhecimento local e a etnopedologia no estudo dos agroecossistemas da Comunidade Quilombola de Brejo dos Crioulos Laudiceio Viana Matos, João Carlos Ker, Irene Maria Cardoso, João Luiz Lani, Carlos Ernesto Gonçalves Reynaud Schaefer

\title{
O CONHECIMENTO LOCAL E A ETNOPEDOLOGIA NO ESTUDO DOS AGROECOSSISTEMAS DA COMUNIDADE QUILOMBOLA DE BREJO DOS CRIOULOS
}

\section{Local knowledge and ethnopedology the study of agroecosystems maroon community of Brejo dos Crioulos (Minas Gerais, Brazil)}

\author{
Laudiceio Viana Matos \\ INCRA, Bahia, Brasil \\ laudimatos@yahoo.com.br \\ João Carlos Ker \\ Universidade Federal de Viçosa, Viçosa, Minas Gerais, Brasil \\ jcker@ufv.br \\ Irene Maria Cardoso \\ Universidade Federal de Viçosa, Viçosa, Minas Gerais, Brasil \\ irene@ufv.br \\ João Luiz Lani \\ Universidade Federal de Viçosa, Viçosa, Minas Gerais, Brasil \\ lani@ufv.br \\ Carlos Ernesto Gonçalves Reynaud Schaefer \\ Universidade Federal de Viçosa, Viçosa, Minas Gerais, Brasil \\ carlos.schaefer@ufv.br
}

Artigo recebido em 02/10/2013 e aceito para publicação em 02/06/2014

RESUMO: O presente trabalho buscou identificar, resgatar e valorizar os saberes tradicionais sobre o solo e os agroambientes, estabelecendo uma articulação destes saberes com o conhecimento científico de cunho acadêmico. Para isso, realizou-se uma estratificação dos ambientes do território quilombola de Brejo dos Crioulos, com base em critérios locais e pelo método pedológico convencional, considerando o solo e sua interface com outros componentes ambientais. Associou-se a caracterização dos agroecossistemas, com a interpretação e reconhecimento da lógica dos sistemas e saberes tradicionais de uso e manejo dos recursos naturais, constatando-se que os quilombolas reconhecem o melhor momento (tempo), o ambiente (a terra, a umidade, o microclima), a espécie e variedade, combinando atividades e elencando o conjunto de práticas que permitem o sustento de suas famílias. A comunidade de Brejo dos Crioulos domina um sistema próprio de estratificação dos ambientes, cuja identidade possibilita ampla referência e articulação ao conhecimento científico acadêmico. A construção de chaves de identificação dos ambientes com base nos critérios dos quilombolas, associada às informações obtidas com base no saber local, ao aprofundamento da caracterização dos ambientes e ao mapeamento de solos contribuíram para a melhor compreensão das estratégias agroalimentares dos quilombolas, alcançando resultados que podem subsidiar processos de planejamento e definições de políticas públicas para o uso sustentável das terras do território quilombola.

Palavras-chave: saber tradicional; etnopedologia; estratificação de ambientes.

DOI: http://dx.doi.org/10.1590/1982-451320140308 
ABSTRACT: This work sought to identify, rescue and value the traditional knowledge about soil and environment, establishing a relationship of this knowledge with scientific knowledge of academic slant. To this end, it was the stratification of the environment of the marron territory of Brejo dos Crioulos, based on local criteria and pedological conventional method, considering the soil and its interface with other environmental components. Associated with the characterization of agroecosystems, with interpretation and recognition of the logic of traditional knowledge use and management of natural resources, by contacting the maroons recognize the best time (time), the environment (soil, moisture, microclimate), the species and variety, combining activities, and casting a set of practices that allow the survival of their families. The community of Brejo dos Crioulos dominates its own system of stratification of environments, whose identity enables comprehensive reference to scientific knowledge and articulation academic. The construction of identification keys of environments based on the criteria of the maroons, combined with information obtained based on local knowledge, to deepen the characterization of environments and mapping of soils contributed to a better understanding of the strategies of agrifood maroon, achieving results that can support planning processes and definitions of public policies for sustainable land use territory of maroon.

Keywords: environmental stratification; agroecosystems; traditional knowledge.

\section{INTRODUÇ̃̃O}

A diversidade ambiental do Norte de Minas Gerais, formada a partir de sua geologia, clima, relevo, condicionantes hídricos e biológicos, viabilizou o estabelecimento de intensas relações sócio-ambientais em paisagens distintas (COSTA, 1999; GONÇALVES, 2000), consolidando o modus vivendi de habitantes de ambientes específicos conforme lógica própria diante dos condicionantes históricos e ambientais da região (DAYRELL, 1998; COSTA, 1999).

Esta diversidade sócio-ambiental criou uma identidade cultural que faz com que as populações do Norte de Minas se diferenciem de acordo com as localidades onde se situam, permitindo a construção de diferentes sistemas cognitivos ou matrizes de racionalidade (TOLEDO, 1996; DIEGUES, 2000; GONÇALVES, 2000).

Portadores de conhecimentos seculares sobre o uso da terra, as populações tradicionais do Norte de Minas sobrevivem às dificuldades com as lavouras tradicionais e aproveitamento dos recursos naturais. No entanto, o saber construído pelas populações tradicionais sobre o ambiente em que vivem, tem sido geralmente desconsiderado em programas de pesquisa e desenvolvimento.

No entanto, muitos estudos reconhecem e comprovam a importância deste conhecimento para o cotejamento responsável e condizente às especificidades de agroecossistemas locais (BARRERA-BASSOLS; ZINCK, 2003; KRASILNIKOV; TABOR, 2003; WINKLERPRINS, 2004; BRIGGS, 2005; BARRERABASSOLS et al., 2006).

Neste sentido, a combinação de ciências naturais e sociais e a consolidação de campos de cruzamento de saberes, como a etnopedologia, passam a contemplar o processo de pensar os ambientes de forma integrada e com a participação dos agricultores, possibilitando abranger o conjunto de fatores interdisciplinares dedicados ao entendimento das interfaces existentes entre os solos, o homem e os outros componentes ecossistêmicos (TABOR, 1992; TOLEDO, 1999; MARQUES, 2001; GUZMÁN, 2002).

A abordagem etnopedológica facilita o resgate do saber tradicional e possibilita a interlocução deste com o conhecimento do meio científico, agilizando e otimizando a caracterização dos solos e dos ambientes do território e subsidia o planejamento de uso sustentável das terras. Por exemplo, as comunidades tradicionais adotam um sistema de manejo que considera especificidades locais, do solo, da água, clima, mercado, cultura e que não é contemplado nas intervenções pedológicas convencionais, mas sim, nas abordagens etnopedológicas.

Nesta perspectiva, que o presente trabalho objetivou: i) estratificar os ambientes segundo critérios locais, considerando o solo e sua interface com os outros componentes ambientais na comunidade 
tradicional quilombola de Brejo dos Crioulos, localizada no Norte de Minas; ii) compreender a lógica dos sistemas produtivos dos quilombolas a partir da sua relação com as especificidades dos diferentes ambientes e iii) caracterizar e aprofundar o estudo dos solos, articulando o saber local ao conhecimento científico.

\section{MATERIAL E MÉTODOS}

\section{Comunidade Tradicional Quilombola de Brejo dos Crioulos}

Comunidades Quilombolas, de acordo com o Art. 2 do Decreto 4.887 de 20/11 de 2003, são "remanescente das comunidades dos quilombos, os grupos étnicos raciais, segundo critérios de auto-atribuição, com trajetória histórica própria, dotados de relações territoriais especificas, com presunção de ancestralidade negra relacionada com a resistência à opressão histórica sofrida".

A comunidade tradicional quilombola de Brejo dos Crioulos está localizada no sertão do Norte de Minas Gerais a 597 km de Belo Horizonte (Figura 1). A área total do território é $17.301,80$ ha, de acordo com planta topográfica elaborada e disponibilizada pelo INCRA-MG.

Figura 1. Comunidade remanescente do quilombo de Brejo dos Crioulos. Localizada nas divisas dos municípios de Varzelândia, São João da Ponte e Verdelândia, Norte de Minas Gerais. O território estende-se transversalmente da margem direita do córrego São Vicente até ultrapassar o rio Arapuim, ao sul.

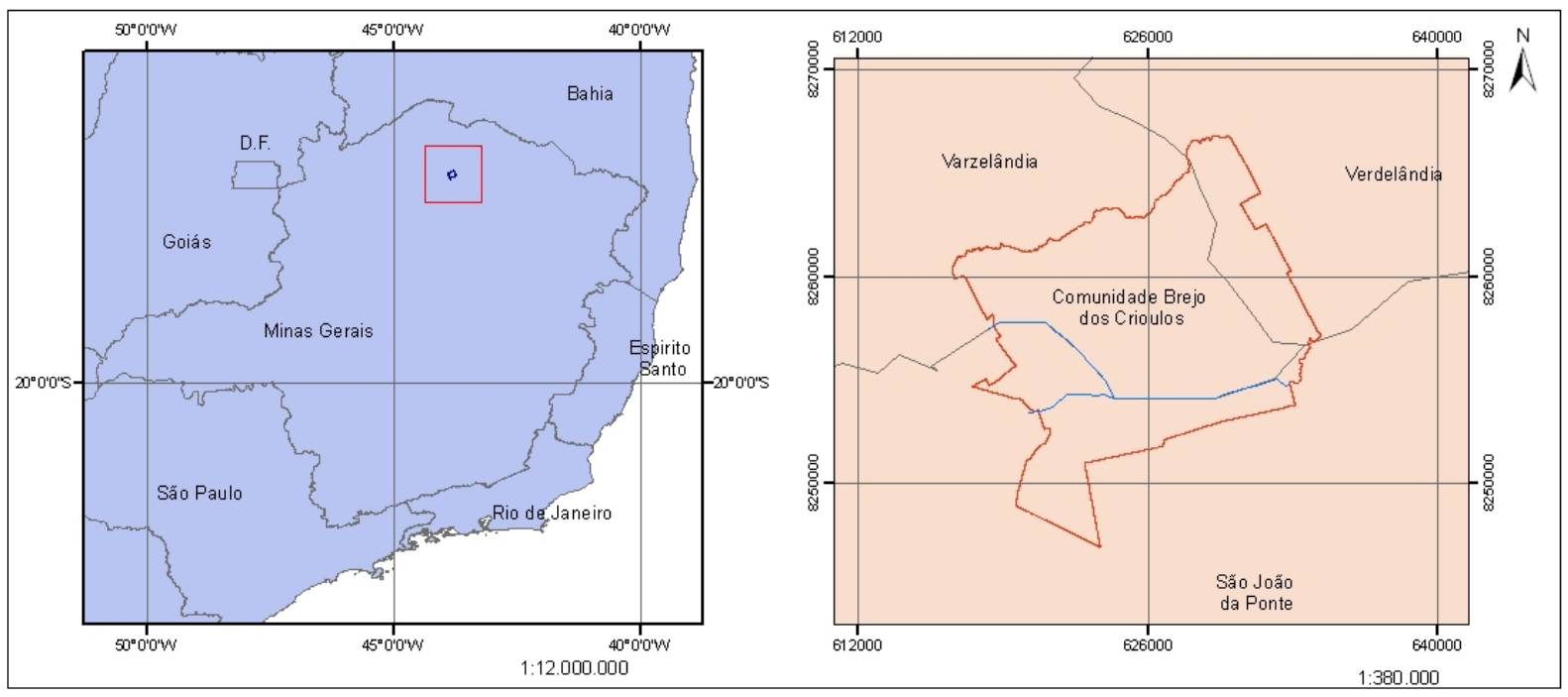

Elaboração dos autores.

A comunidade surgiu a partir de condições históricas e sócio-ambientais específicas, corresponde a uma área historicamente ocupada por populações negras refugiadas dos antigos quilombos desde meados do século XVIII, que diante de situações geográficas e ambientais favoráveis à sua "invisibilidade", possibilitou a reprodução social de seu povo até os dias atuais (COSTA, 1999). O termo invisibilidade foi utilizado por Costa (1999), como a possibilidade dessas populações instalarem-se na região onde outros grupamentos humanos não conseguiriam, no caso de
Brejo dos Crioulos, por causa da grande incidência de malária. A população negra era resistente a esta doença, diferentemente dos brancos, que só chegaram mais tarde com a erradicação da doença.

Esse território, antes utilizado de forma comunal, hoje se encontra fragmentado por fazendas extensas, que prensaram os quilombolas em pequenas franjas de terras, dando origem a pequenos conglomerados humanos que formam os atuais núcleos de moradia. De acordo com o diagnóstico realizado durante a elaboração do Laudo Antropológico (RTID, 2004), 
Brejo dos Crioulos apresenta uma população aproximada de 2.042 pessoas, integradas em 411 famílias.

Brejo dos Crioulos foi escolhida por se constituir de povos revestidos de um etos social representativo das comunidades tradicionais nortemineiras, apresentando uma relação estreita e complexa com seu território ou ambiente, historicamente marcada por um processo coevolutivo, de asserção e identificação do conhecimento gerado localmente sobre os aspectos ambientais, culturais, sócio-econômicos e políticos, assim como por uma constante problemática de gestão territorial e sustentabilidade agroambiental. Foram considerados, ainda, a existência de processos organizativos, a facilidade de acesso e o interesse da comunidade em participar de todas as etapas da pesquisa, observando-se a compatibilidade e atendimento dos objetivos e metas propostas no trabalho, além do cuidado de se evitar a geração de expectativas por parte dos quilombolas, as quais a pesquisa não pudesse atendê-las.

Além disso, a comunidade carece de estudos e sistematização de informações que dêem subsídios à elaboração de propostas de trabalho condizentes com sua realidade e que possam contribuir na reivindicação de políticas agrícolas dirigidas às populações tradicionais.

O projeto de pesquisa foi apresentado inicialmente ao Centro de Agricultura Alternativa do Norte de Minas (CAA/NM), organização não governamental que atua na comunidade e ao Sindicato dos Trabalhadores Rurais de Varzelândia (STR). A experiência acumulada por essas duas instituições na assessoria técnica às organizações de agricultores do Norte de Minas foi fundamental na elaboração e execução desta pesquisa, principalmente do ponto de vista metodológico. Em seguida o projeto foi apresentado à comunidade de Brejo dos Crioulos. Tanto as organizações quanto os membros da comunidade se prontificaram a apoiar e participar de sua execução.

As etapas metodológicas para a realização desta pesquisa tiveram início com um extenso levantamento do material bibliográfico sobre a comunidade de Brejo dos Crioulos, dentre eles, estudos antropológicos sobre o estabelecimento histórico do quilombo e sua reprodução social, contemplando ainda aspectos políticos, sócio-econômicos e ambientais (COSTA,
1999).

$\mathrm{Na}$ definição da abordagem metodológica, procurou-se atender os objetivos previstos dentro de uma perspectiva da lógica do saber acumulado pelos quilombolas, articulando-o com o saber científico, na tentativa de fornecer subsídios para a construção de processos de planejamento de uso sustentável dos agroecossistemas.

Procurou-se melhor compreender os fundamentos da racionalidade quilombola, especialmente sua relação com a terra e ambientes, condicionando a formulação de estratégias produtivas específicas diante da diversidade ambiental. Evitou-se a antecipação do levantamento e caracterização ambiental a partir da abordagem eticista, resguardando em primeira análise, a visão local. De acordo com Harris (2000), "eticista" refere-se às descrições e interpretações sob o olhar do observador (membro de fora, aqui reconhecido como pesquisador), em detrimento às análises "emiscistas", próprias dos participantes (os quilombolas). As informações foram sistematizadas a partir do saber tradicional dos quilombolas, mas teve-se a preocupação constante de articulá-las com o conhecimento gerado no meio científico, considerando a complexidade das informações pertinentes ao manejo dos agroecossistemas e metodologia apropriada para incorporar o conhecimento das comunidades locais (RESENDE, 1995). O trabalho de campo envolveu três fases, a saber:

\section{Fase I - O complexo produtivo e a caracterização ambiental: o território, quem o habita e suas estra- tégias reprodutivas}

Nesta fase, manteve-se o foco no conhecimento local, com o levantamento de questões históricas de uso e ocupação do território, as práticas antigas e atuais; as datas marcantes que refletiram em mudanças de hábitos; as adversidades climáticas (os períodos de seca, as "cheias", os tempos de fartura ou de fome). Consistiu na tentativa de decodificação do corpus a partir de um diálogo paciente e meticuloso (TOLEDO, 1996). Vale ressaltar que esta etapa ocorreu no mês de abril, que corresponde ao final do período chuvoso, período da "descida das águas".

Durante o trabalho, procurou-se realizar, jun- 
tamente com os quilombolas, uma descrição detalhada e factível dos ecossistemas que formam o espaço produtivo da área em estudo, associado à visão do sistema produtivo para o núcleo familiar e sua relação com a dimensão do território como um todo.

Identificaram-se as atividades que prescrevem um manejo comunal das terras, e fez-se assim, uma caracterização, descrição e estudo dos solos nos ambientes locais, bem como, a vegetação, fauna, relevo, clima, ciclo hidrológico e outros (RESENDE, 1995; TOLEDO, 1996; ALTIERI, 2002).

Foram utilizados métodos e técnicas de pesquisa do Diagnóstico Rural Participativo para a obtenção de dados e informações relevantes na condução da pesquisa com a abordagem do conhecimento local (CHAMBERS, 1994). Cada ferramenta foi utilizada de acordo com os objetivos a serem atingidos, a característica do grupo e a conjuntura do momento, implicando em uma constante adaptação das ferramentas (GEIULFUS, 2000). Durante a pesquisa de campo foram utilizadas as seguintes técnicas coletivas: caminhadas transversais com a elaboração de transectos, calendário sazonal, mapeamentos dos sistemas agroalimentares e unidades da paisagem, diagramas construídos em reuniões comunitárias, incursões nas unidades produtivas familiares (UPF) e a articulação das informações com atividades como debates a partir das reflexões e dos conhecimentos teóricos sobre a prática cotidiana. Foram realizadas entrevistas com informantes qualificados e lideranças locais (ALFONSO, 1990; BECKER, 1999).

Todo o trabalho foi conduzido utilizando-se uma linguagem simples, procurando-se estabelecer diálogo com o máximo de pessoas possível (ERNESTO SOBRINHO, 1983; LANI, 1987; CARDOSO, 1993; RESENDE, 1995; CORREIA et al., 2004).

As informações desta etapa subsidiaram a elaboração de uma versão preliminar da chave de identificação dos ambientes e a noção da distribuição espacial dos ambientes em cada núcleo de moradia.

\section{Fase II - A abordagem etnopedológica: o solo como elemento estratificador}

As atividades desta etapa foram desenvolvidas um mês após a primeira fase, já com a sistemati- zação das informações obtidas anteriormente e com a participação de uma equipe de pesquisadores.

Objetivou nesta etapa a identificação, resgate e compreensão do conhecimento local sobre os ambientes, as terras e os sistemas agroalimentares adotados pelos quilombolas, assim como a influência das condições sócio-econômicas e políticas sobre a dinâmica da comunidade e do ambiente em que estão inseridos (TOLEDO, 1996; GEILFUS, 1997; DAYRELL, 1998; TOLEDO et al., 1999).

Utilizou-se de métodos e técnicas de pesquisa do Diagnóstico Rural Participativo (DRP) para a abordagem etnopedológica adotada neste estudo (CHAMBERS, 1994). Estas técnicas foram adaptadas de acordo com o desenvolvimento do trabalho. Dentre as técnicas do DRP, utilizou-se entrevistas semi-estruturadas, mapas, coleta e caracterização participativa dos solos segundo os critérios e nomenclatura local. Dentre as características do solo, procurou-se analisar a cor, textura, estrutura e fertilidade natural. Elaborou-se também o calendário de produção da comunidade. Adotou-se ainda a observação participante, uma técnica da etnografia, para o acompanhamento das práticas cotidianas dos quilombolas, com atenção especial para os diferentes ambientes, solos, paisagem, estratégias produtivas e aproveitamento dos recursos naturais. Todas as informações foram registradas utilizando-se cadernetas de campo e gravadores (ALFONSO, 1990; BECKER, 1999).

O GPS foi utilizado para a localização geográfica dos pontos de coleta e observação, localização de núcleos de moradia e delimitação de unidades geoambientais.

Durante esta fase foram coletadas amostras de solo para análise em laboratório. A coleta de solo será descrita em tópico específico. Ainda no campo, os quilombolas realizaram uma caracterização expedita da cor, textura e aptidão agrícola dos solos segundo critérios locais, além da identificação da posição dos diferentes ambientes na paisagem. As informações desta etapa possibilitaram a estratificação ambiental e a elaboração da chave de identificação dos ambientes com base no conhecimento dos quilombolas. 


\section{Fase III: O levantamento de solos e a caracterização dos ambientes}

Priorizou-se nesta etapa a análise "eticista", possibilitando a caracterização e estratificação da paisagem de acordo com os critérios elaborados no meio científico. Não houve o envolvimento dos agricultores durante as atividades.

No método de mapeamento pedológico convencional e na caracterização ambiental, o trabalho de campo é fundamental, possibilitando a coleta de dados da paisagem, a descrição das características dos solos e a identificação dos limites entre unidades de mapeamento, compondo um conjunto de áreas de solos com relações e posições definidas na paisagem (EMBRAPA, 1995 e 2006). Para isso, as atividades foram orientadas de acordo com o "Manual de Descrição e Coleta de Solo no Campo" (SANTOS et al., 2005) e os "Procedimentos Normativos de Levantamentos Pedológicos" (EMBRAPA, 1995).

O trabalho de campo envolveu a coleta de amostras de solo para a caracterização física, química e mineralógica, em diferentes geoambientes, utilizando-se cilindros para a aplicação de testes de resistência a penetração, micro e macro porosidade e densidade. Com a finalização das atividades de campo, esboçou-se o mapa de solos segundo a percepção do técnico, acompanhado de uma legenda onde foram descritas as classes de solos observadas (compatíveis com a escala de trabalho) e que compuseram as respectivas unidades de mapeamento (RESENDE et al., 2002).

A utilização de recursos cartográficos, como imagem de satélite, o modelo de elevação digital (apresenta as curvas de nível com o distanciamento de $10 \mathrm{~m}$ ) e uma carta planimétrica da área, elaborada pelo INCRA/MG (escala 1:40.000), subsidiaram a espacialização das unidades do mapeamento de todo o território.

\section{Geoprocessamento}

$\mathrm{O}$ trabalho de processamento de imagens e sistema de informações geográficas (SIG) concentrou-se no Laboratório de Geoprocessamento do Departamento de Solos da Universidade Federal de Viçosa. Para isso foram utilizadas imagens do satélite CBERS obtidas junto ao sítio do INPE na internet, referentes ao sobrevôo da área no dia 18 de setembro de 2006, formando a cena 153/118, em projeção UTM DATUM SAD 69 e fuso 23S. Também foram obtidos dados de altimetria da imagem SRTM (Shuttle Radar Topographic Mission) fornecidas pelo GEOMINAS, a qual viabilizou a elaboração do Modelo de Elevação Digital (MDE), consistindo em uma base altimétrica do território que permitiu a sistematização dos transectos. O perímetro do território e as estradas vicinais foram repassados pelo INCRA/MG, diretamente por meio de arquivo digital específico.

\section{Análises Laboratoriais}

Na fase II, foram coletadas 76 amostras de solos em diferentes áreas do território quilombola. As amostras foram coletadas às profundidades de $0-20 \mathrm{~cm}$ e de $20-40 \mathrm{~cm}$, reconhecidas como as porções mais trabalhadas pelos quilombolas na condução de seus agroecossistemas.

Durante a fase III, as amostras foram coletadas a partir da descrição completa em trincheiras de 4 perfis de solo, mais a coleta em 17 perfis como seção de controle, que se refere à camada superficial do horizonte A e outra porção representativa do horizonte diagnóstico subsuperficial. As coletas somaram um número total de 58 amostras em 21 classes de solo, sendo todas as amostras submetidas à caracterização morfológica de cor seca e úmida, estrutura e consistência seca, úmida e molhada. A cor do solo foi determinada por comparação com padrões contidos na Soil Color Charts em amostras secas e umedecidas (MUNSELL, 1994). A composição granulométrica foi determinada segundo a Embrapa (1997) e Ruiz (2005ab). A determinação da argila dispersa em água, densidades das partículas e a do solo, seguiu-se a metodologia da Embrapa (1997). As análises e caracterização químicas foram realizadas no Departamento de Solos da Universidade Federal de Viçosa - UFV.

$\mathrm{O} \mathrm{pH}$ foi determinado em água e em solução de $\mathrm{KCl}$ a $1 \mathrm{~mol} \mathrm{~L}^{-1}$ na suspensão solo-solução com proporção de 1:2,5. As concentrações de cálcio e magnésio trocáveis foram extraídas com $\mathrm{KCl}$ a $1 \mathrm{~mol}$ $\mathrm{L}^{-1}$ na proporção de 1:20, sendo quantificados por espectrometria de absorção atômica. O sódio e potássio 
trocáveis foram extraídos com solução de $\mathrm{Mehlich}^{-1} \mathrm{e}$ determinados por fotometria de chama. $\mathrm{O} \mathrm{Al}^{3+}$ foi extraído em $\mathrm{KCl}$ a $1 \mathrm{~mol} \mathrm{~L}^{-1}$ e determinado por titulometria com $\mathrm{NaOH}$. $\mathrm{O} \mathrm{H}+\mathrm{Al}$ foram extraídos por acetato de cálcio a $0,5 \mathrm{~mol} \mathrm{~L}^{-1} \mathrm{em}$ pH 7,0 e quantificados por titulometria com $\mathrm{NaOH}$. O P disponível foi extraído pelo extrator Mehlich $^{-1}$ e quantificado pelo método do ácido ascórbico (DEFELIPO e RIBEIRO, 1997). A acidez potencial foi determinada por titulação com $\mathrm{NaOH}\left(0,025 \mathrm{~mol} \mathrm{~L}^{-1}\right)$ da extração de acetato de cálcio $0,5 \mathrm{~mol} \mathrm{~L}^{-1}$ a $\mathrm{pH} 7,0$. O carbono foi determinado de acordo com o método de Yeomans e Bremner (1988) adaptado por Mendonça e Matos (2005).

\section{RESULTADOS E DISCUSSÃO}

Em Brejo dos Crioulos, os quilombolas estratificaram quatro macroambientes, considerando-se inicialmente a posição no relevo e umidade do solo, a saber: "carrasco", "encosta ou cultura vermelha", "vazante" e "brejo" (Figura 2).

Figura 2. Bloco diagrama ilustrando as unidades da paisagem identificadas pelos quilombolas no território de Brejo dos Crioulos

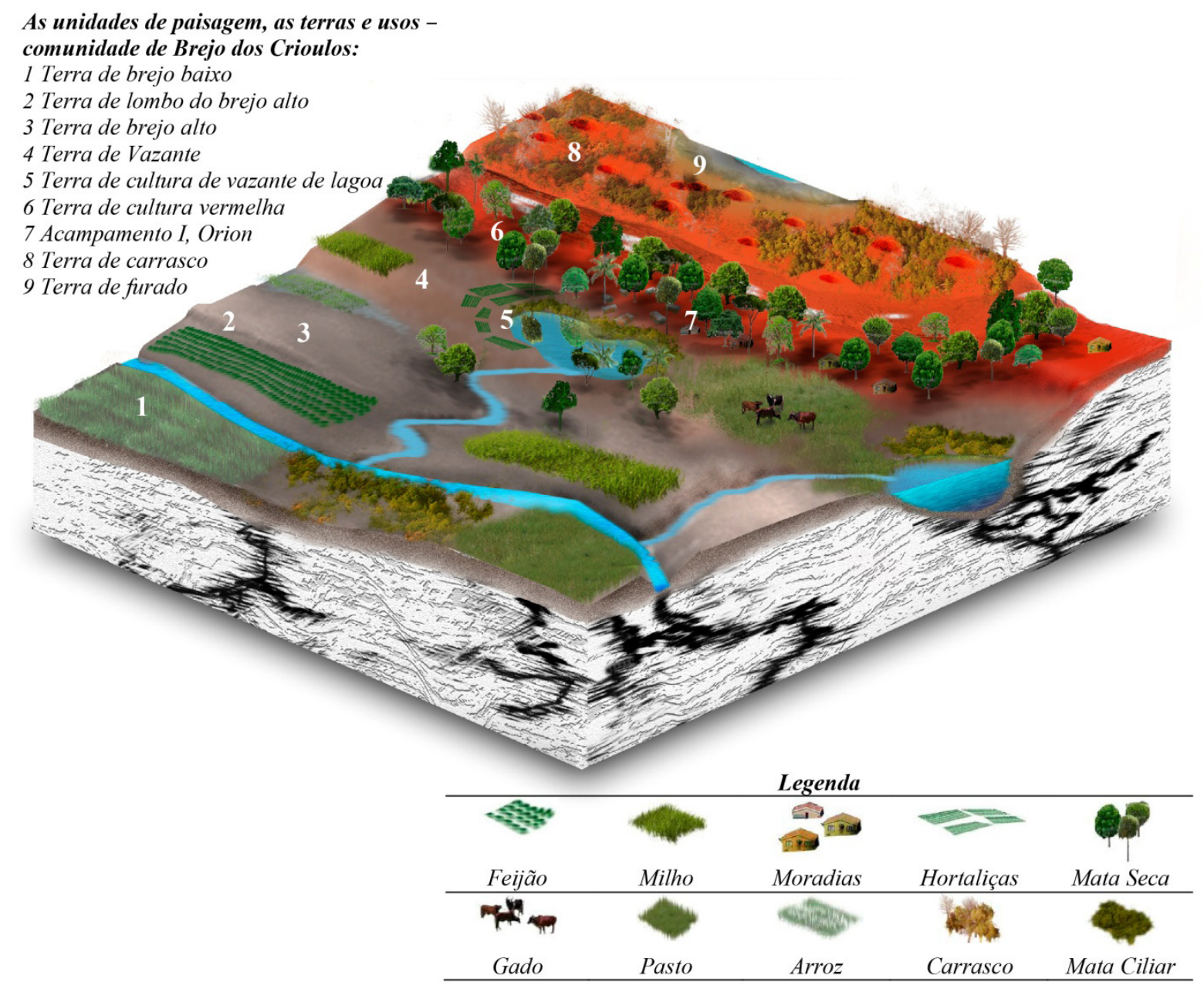

Elaboração dos Autores.

Apesar da posição do relevo e umidade do solo apresentarem-se como fatores predominantes, esta visão é ampliada à medida que o estudo de cada ambiente é aprofundado, elucidando a percepção de que este é produto de uma inter-relação intensa entre diversos componentes da paisagem.

Este aprofundamento a partir da hierarquização de cada macroambiente revela a participação de 
outros fatores e atributos percebidos pelos quilombolas como características importantes na distinção intra-macroambientes, identificando assim, os microambientes da paisagem. Para isso, os quilombolas reconhecem e integram os diversos fatores ambientais e atributos morfológicos, como a localização, cor, estrutura, textura, vegetação. De acordo com a dinâmica proveniente da inter-relação desses fatores, associados aos climáticos, os quilombolas estabelecem as diferentes formas de uso, mostrando uma lógica própria e coerência na condução de seus sistemas de produção (JOHNSON, 1974).

Na identificação dos macroambientes, considerou-se a localização como o principal atributo, associado à linha de umidade criada com o ciclo das águas. Já na identificação dos microambientes ocorre uma combinação de atributos que os quilombolas fazem muito bem, comprovando a capacidade acurada dos quilombolas de compreender a complexidade ambiental. Entre os atributos mais utilizados encontram-se a cor, textura e umidade, que associados às características químicas ajudam no reconhecimento dos principais usos e ocupação do solo pelos agricultores, inclusive o tipo de vegetação com base em critérios locais. Em alguns casos houve também a associação com a estrutura, mas este atributo é pouco utilizado pelos agricultores na distinção dos ambientes.

A cor desempenha forte influência para uma evidente determinação dos limites entre os macroambientes, por exemplo, entre a "vazante" e a "cultura vermelha", mas quando os macroambientes apresentam colorações muito semelhantes, exige-se a incorporação de outros atributos para a distinção e delimitação dos ambientes, como a vegetação.

Estas informações indicam que, após a localização e umidade, não existe uma sequência definida dos atributos, componentes e fatores ambientais para a efetivação da distinção dos macroambientes e que outros componentes ambientais e atributos podem ser incorporados no processo de hierarquização. A experiência com o cultivo em diferentes ambientes constitui outra prática eficaz de distinção ambiental e de identificação das culturas, variedades e formas de manejo que se adaptam a cada local.

Dentro de cada macroambiente, considerandose até os microambientes, identificou-se um sistema de manejo específico para o tipo de solo formado nestas distintas áreas. As possibilidades de manejo são diversas, consolidadas a partir de uma estratégia agroalimentar construída ao longo dos anos, demonstrando serem efetivas com uma combinação de práticas e observações, seja por meio da seleção de espécies ou variedades que mais se adaptam a um determinado local, a época adequada para a realização do plantio, o tipo de preparo do solo, os consórcios, a rotação de culturas, pousio, vinculação da criação dos animais com as áreas de cultivo e até o "manejo das águas", resultado de um profundo conhecimento construído pelos quilombolas em relação à dinâmica das águas em seu território, estabelecida a partir de dois grandes marcos: "a subida das águas ou das cheias", início do período chuvoso, e a "descida das águas", início do período de seca, fenômenos que representam sérias implicações no sistema de manejo dos quilombolas (Figura 3).

Figura 3. Ilustração da linha de umidade durante os períodos de "descida das águas" (a) e de "subida das águas" (b), respectivamente, influenciando a delimitação da transição do complexo aluvial, mais especificamente vazante, com a cultura vermelha.
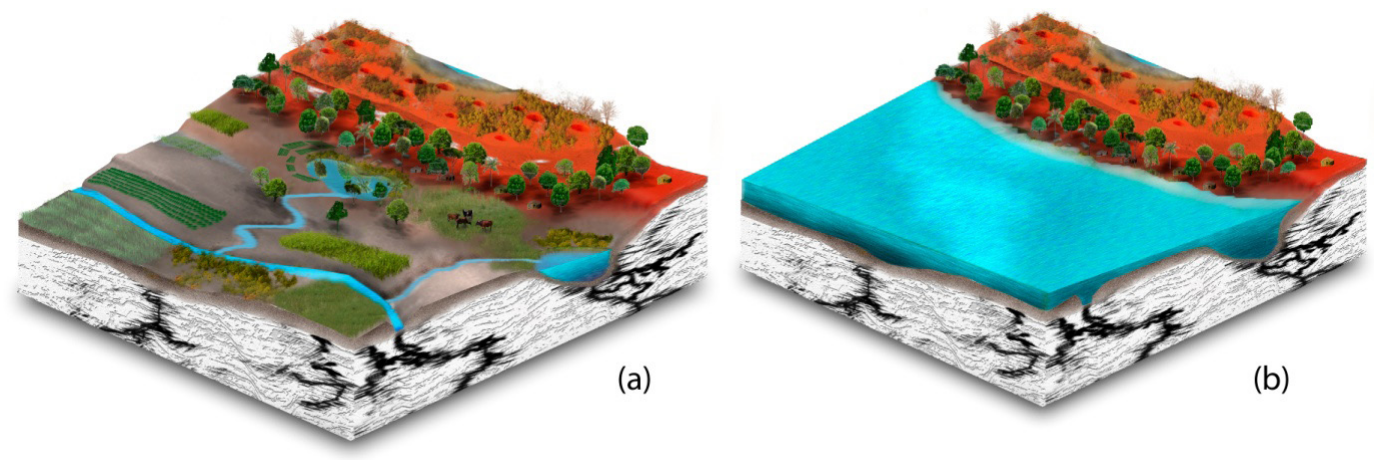

Elaboração dos Autores. 
A partir do aprofundamento dos critérios de estratificação ambiental, incorporando a localização e umidade, a cor e textura, construiu-se a chave de identificação dos ambientes do território de Brejo dos Crioulos (Tabelas 1 e 2), com base nas informações fornecidas pelos quilombolas. A estratificação é uma ferramenta que auxilia na compreensão e caracterização das unidades da paisagem local, além de apresentar um formato que facilita a compreensão dos usuários locais e o diálogo entre as diferentes formas do conhecimento, tradicional e científico, a respeito da diversidade, caracterização e adequação dos ambientes (RESENDE, 1995).

A cada ambiente identificado pelos quilombolas, associou-se as informações obtidas no levantamento e classificação convencional e aos dados analíticos do solo (Tabelas 1 e 2). Os diferentes ambientes correspondem a determinadas classes de solo, que variam de acordo com as condições de cada local, estas podem ocorrer em pequenas franjas ou se reproduzirem em grandes extensões ao longo do território. Para facilitar o entendimento do conhecimento local, neste trabalho será adotado o termo "terra" para designar "solo", quando se trata das informações repassadas pelos quilombolas, critério também reportado em vários estudos em comunidades tradicionais (CARDOSO, 1993; DAYRELL, 1998; ALVES, 2004, 2005; CORREIA, 2005; DAYRELL, 2006; CORREIA et al., 2007).

Toda terra considerada de "cultura" pelos quilombolas, foi constatado nos resultados analíticos, que se trata de solos eutróficos, com boa saturação por bases e sem salinidade, sendo propícias aos cultivos mais nobres (mantimentos que participam diretamente da dieta alimentar, como: o arroz, feijão, milho, fava, hortaliças e outras) dos quilombolas.

As terras do "brejo" e "vazante" (Tabela 1) destacam-se pela boa fertilidade natural e maior capacidade de retenção de água em plena região semi-árida, na estratégia produtiva dos quilombolas. As "terras de cultura" (Tabela 2) estão subdivididas em dois grupos, de acordo com a posição no relevo: nas encostas ocorrem as "terras de cultura vermelha", de menor produtividade, especialmente nas áreas de transição com as "terras do carrasco", e as "terras de cultura preta ou roxa", nas áreas do complexo aluvial ("brejo" e "vazante"). Estas últimas estão associadas aos processos de redução dos compostos de ferro presentes nestes solos devido à menor disponibilidade de oxigênio em condições de má drenagem e também ao incremento no teor de matéria orgânica nas camadas superficiais (RESENDE, 1995; RESENDE et al., 2002). Apesar de ambas serem de cultura, os quilombolas relatam que as terras de colorações mais escuras propiciam maiores produtividades nas lavouras. 
Tabela 1. Chave de identificação e distinção das unidades de paisagem Brejo e Vazante, Brejo dos Crioulos, Varzelândia, Minas Gerais

\begin{tabular}{|c|c|c|c|c|}
\hline \multicolumn{2}{|c|}{ 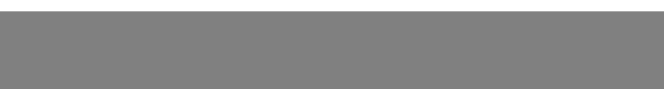 } & Cor & Textura & $\mathrm{SiBCS}$ \\
\hline \multicolumn{5}{|l|}{ Macroambiente brejo } \\
\hline \multirow{4}{*}{$\begin{array}{l}\text { Baixada } \\
\text { (ambiente de maior } \\
\text { umidade) }\end{array}$} & \multirow{4}{*}{$\begin{array}{l}\text { Brejo (formado às } \\
\text { margens do Rio } \\
\text { Arapuim e lagoas } \\
\text { adjacentes) }\end{array}$} & \multirow{2}{*}{$\begin{array}{l}\text { Barro branco (ama- } \\
\text { relado) }\end{array}$} & $\begin{array}{l}\text { Racha (argila, argi- } \\
\text { lo-siltosa) }\end{array}$ & $\begin{array}{l}\text { RYbe, GXbe (brejo } \\
\text { alto e baixo) }\end{array}$ \\
\hline & & & $\begin{array}{l}\text { Misturado - areia } \\
\text { (franco-argilo-are- } \\
\text { nosa) }\end{array}$ & $\begin{array}{l}\text { RYbe, GXbe (brejo } \\
\text { alto e baixo) }\end{array}$ \\
\hline & & \multirow{2}{*}{ Terra preta (cinza) } & $\begin{array}{l}\text { Racha - barrento } \\
\text { (argila, argilo-sil- } \\
\text { tosa) }\end{array}$ & $\begin{array}{l}\text { RYbe, GXbe (brejo } \\
\text { alto e baixo) }\end{array}$ \\
\hline & & & $\begin{array}{l}\text { Misturado - areia } \\
\text { (franco-argilo-are- } \\
\text { nosa) }\end{array}$ & $\begin{array}{l}\text { RYbe, GXbe (brejo } \\
\text { alto e baixo) }\end{array}$ \\
\hline \multicolumn{5}{|c|}{ Macroambienta vazante } \\
\hline \multirow{7}{*}{$\begin{array}{l}\text { Terço inferior das } \\
\text { encostas (menor } \\
\text { umidade em relação } \\
\text { ao brejo) }\end{array}$} & \multirow{4}{*}{$\begin{array}{l}\text { Vazante do Rio Ar- } \\
\text { apuim }\end{array}$} & \multirow{2}{*}{ Rosa } & $\begin{array}{l}\text { Barro (franco-argi- } \\
\text { loso) }\end{array}$ & \multirow{4}{*}{ CXbe, PVe } \\
\hline & & & $\begin{array}{l}\text { Arenoso (franco- } \\
\text { argilo-arenosa) }\end{array}$ & \\
\hline & & Clara & $\begin{array}{l}\text { Barro (franco-argil- } \\
\text { oso-arenosa) }\end{array}$ & \\
\hline & & Escura & $\begin{array}{l}\text { Barro (franco-argi- } \\
\text { loso) }\end{array}$ & \\
\hline & $\begin{array}{l}\text { Vazante do Córrego } \\
\text { São Vicente }\end{array}$ & Roxa & $\begin{array}{l}\text { Areia + barro (tex- } \\
\text { tura variando de } \\
\text { franco-argilosa a } \\
\text { franco-argilo-are- } \\
\text { nosa) }\end{array}$ & PVAe, LVe, CXbe \\
\hline & $\begin{array}{l}\text { Vazante dos Fura- } \\
\text { dos }\end{array}$ & $\begin{array}{l}\text { Roxa (vermelho- } \\
\text {-amarelo, com des- } \\
\text { taque ao amarelo) }\end{array}$ & $\begin{array}{l}\text { Areia + barro (tex- } \\
\text { tura varia de franco- } \\
\text {-argilosa a franco) }\end{array}$ & LVAd, GXbe \\
\hline & Vazante das lagoas & Roxa & $\begin{array}{l}\text { Areia + barro (tex- } \\
\text { tura varia de argila } \\
\text { a muito argolosa } \\
\text { próxima à lagoa) }\end{array}$ & GXbe, CXbe \\
\hline & & Org. dos Autores. & & \\
\hline
\end{tabular}


Tabela 2. Chave de identificação e distinção das unidades de paisagem do macroambiente Cultura Vermelha e Carrasco, Brejo dos Crioulos, Varzelândia, Minas Gerais

\begin{tabular}{|c|c|c|c|c|}
\hline \multirow{2}{*}{\multicolumn{2}{|c|}{ Macroambiente Cultura Vermelha }} & Cor & Textura & \multirow[t]{2}{*}{ SiBCS } \\
\hline & & & & \\
\hline \multirow{3}{*}{$\begin{array}{l}\text { Encosta (limite } \\
\text { de ocorrência das } \\
\text { terras de cultura. } \\
\text { A maior limitação } \\
\text { dessas áreas é o dé- } \\
\text { ficit hídrico) }\end{array}$} & $\begin{array}{l}\text { Cultura vermelha } \\
\text { mista }\end{array}$ & $\begin{array}{l}\text { Vermelha (vermelha } \\
\text { menos intenso) }\end{array}$ & $\begin{array}{l}\text { Areia, menos bar- } \\
\text { ro (Argilo-arenosa, } \\
\text { franco-argilosa e } \\
\text { franco-argilosa are- } \\
\text { nosa) }\end{array}$ & $\mathrm{LVd}$ \\
\hline & $\begin{array}{l}\text { Cultura vermelha } \\
\text { típica }\end{array}$ & $\begin{array}{l}\text { Vermelha (vermelho } \\
\text { escuro) }\end{array}$ & $\begin{array}{l}+ \text { Argilo (Argila, } \\
\text { franco-argilosa e } \\
\text { menor ocorrência } \\
\text { de franco-argilo- } \\
\text {-arenoso) }\end{array}$ & $\mathrm{LVe}$ \\
\hline & $\begin{array}{l}\text { Cultura vermelha } \\
\text { de vazante }\end{array}$ & $\begin{array}{l}\text { Vermelha (verme- } \\
\text { lho escuro e bruno, } \\
\text { maior teor de maté- } \\
\text { ria orgânica) }\end{array}$ & $\begin{array}{l}+ \text { Areia (Franco- } \\
\text {-argilo-arenosa, } \\
\text { franco-argilosa) }\end{array}$ & LVe, CXbe, PVe \\
\hline \multicolumn{5}{|c|}{ Macroambiente Carrasco } \\
\hline \multirow[t]{2}{*}{$\begin{array}{l}\text { Topo (áreas de me- } \\
\text { nor fertilidade natu- } \\
\text { ral, sujeita a déficit } \\
\text { hídrico. Presença } \\
\text { de murundus) }\end{array}$} & $\begin{array}{l}\text { Carassco = catan- } \\
\text { duba }\end{array}$ & Vermelha & $\begin{array}{l}\text { - Areia (Argilo- } \\
\text { arenosa, argila) }\end{array}$ & $\mathrm{LVd}$ \\
\hline & $\begin{array}{l}\text { Carrasco entre to- } \\
\text { pos (áreas entre as } \\
\text { partes mais eleva- } \\
\text { das do carrasco e } \\
\text { nas proximidades } \\
\text { dos furados) }\end{array}$ & $\begin{array}{l}\text { Vermelha (pode ser } \\
\text { mais escuro) }\end{array}$ & $\begin{array}{l}+ \text { Areia (Franco- } \\
\text { - argilo-arenosa, } \\
\text { franco-argilosa, ar- } \\
\text { gilosa) }\end{array}$ & $\mathrm{LVd}$ \\
\hline
\end{tabular}

Vale ressaltar que as "terras do carrasco" (Tabela 2) no território de Brejo dos Crioulos são de coloração vermelha ou vermelho-amarela e não são consideradas como de cultura por não apresentarem aptidão para os cultivos mais nobres. O potencial do "carrasco" é reconhecido na integração e diminuição da pressão sobre os agroecossistemas. Nestas áreas de uso comunal aproveita-se a flora nativa não apenas como lenha, mas também para forragem animal, pequenas construções, móveis, equipamentos e ferramentas de uso agrícola e doméstico, além de suas possibilidades alimentares (frutos nativos), mel de 
abelhas silvestres e plantas medicinais.

A lógica das distinções ambientais associadas ao manejo também é constatada em outras comunidades tradicionais, conforme se observou no estudo etnopedológico conduzido nas terras indígenas Pankararé no Raso da Catarina-BA, quando se identificou que os critérios de distinção dos ambientes para essa comunidade indígena estão associados ao relevo e fertilidade natural (BANDEIRA, 1996).

A capacidade de observação e percepção dos componentes ambientais se traduz no cotidiano das populações tradicionais, tanto nos aspectos práticos (praxis), como a compreensão do manejo adequado para cada tipo de terra e ambiente (corpus), bem como a sua ligação com os aspectos culturais e acepções cognitivas (kosmos), ligadas inclusive, às nomenclaturas das localidades, objetos, apelidos e outros.

Os quilombolas de Brejo dos Crioulos nomearam comunidades, utensílios e objetos com base na crença e aspectos fisiográficos do território, e da mesma forma estratificaram e deram nomes às unidades da paisagem. A localização na paisagem associada à umidade foram os fatores mais utilizados pelos quilombolas na estratificação do ambiente em grandes unidades no território de Brejo dos Crioulos, aqui chamados de "macroambientes". Este critério foi corroborado por Cardoso (1993) em estudo de estratificação de ambientes com pequenos agricultores na Zona da Mata, mesorregião do estado de Minas Gerais.

A percepção dos quilombolas sobre o ambiente de Brejo dos Crioulos é mais complexa do que aparenta, sendo construída e evoluída através de relações de convivência com a diversidade de ambientes e seus condicionantes físico-químicos e biológicos. A comunidade local tornou-se, assim, capaz de identificar e reconhecer nuances e pequenas variações ambientais, que, apesar de negligenciadas por métodos científicos, parecem muito relevantes quando se busca desenvolver práticas de manejo diferenciadas, potencializando as aptidões locais, e confrontando as limitações naturais.

\section{CONCLUSÕES}

O território quilombola de Brejo dos Crioulos é formado por ambientes que se integram a partir das estratégias agroalimentares desenvolvidas pelos quilombolas ao longo dos anos, fruto da relação de convivência homem-ambiente. Os quilombolas dominam um sistema próprio de estratificação dos ambientes, com base em uma lógica que pode ser explicada, interpretada e articulada ao conhecimento gerado no meio científico. Seus sistemas de produção reconhecem as variáveis e dinâmicas de tempo, clima, cultivo e ambiente, combinando atividades e selecionando práticas que permitem a segurança social e material de suas famílias.

Informações recolhidas com base no saber local, o aprofundamento da caracterização dos ambientes mediado pelo diálogo etnocientífico e o mapeamento de solos contribuíram para a melhor compreensão das estratégias agroalimentares dos quilombolas no norte de Minas Gerais. A abordagem etnopedológica possibilitou a geração de informações que contemplam aspectos ambientais, produtivos e culturais, importantes não somente para as análises e interpretações científicas, mas principalmente na construção de um processo de planejamento de uso sustentável da terra que privilegie a busca por modelos de produção mais duradouros, equilibrados e resistentes às pressões econômicas externas.

\section{AGRADECIMENTOS}

Os autores agradecem ao CNPq-Brasil e à Fundação de Amparo à Pesquisa de Minas Gerais pelos auxílios concedidos para a realização da pesquisa.

\section{REFERÊNCIAS}

ALFONSO, J. M. La investigación em antropologia social. Barcelona: Editorial Ariel, 1990. 237 p.

ALTIERI, M. Agroecologia: bases científicas para uma agricultura sustentável. Guaíba: Agropecuária, 2002. $592 \mathrm{p}$.

BANDEIRA, F. P. F. Um estudo em perspectiva: etnopedologia e etno-ecogeografia do grupo indígena Pankararé. Cad. Geociências (UFBA). Salvador, 5: 107-128. 1996. 
BARRERA-BASSOLS, N.; ZINCK, J. A. Ethnopedology: a world view on the soil knowledge of local people. In: WINKLER PRINS, A. M. G. A. \& SANDOR, J. A., eds. Ethnopedology. Geoderma, 111:171-195, 2003. DOI: http://dx.doi.org/10.1016/ S0016-7061(02)00263-X

BARRERA-BASSOLS, N.; ZINCK, J. A.; RANST, E. V. Symbolism, knowledge and management of soil and land resources in indigenous communities: ethnopedology at global, regional and local scales. Catena, v. 65, p. 118-137, 2006. DOI: http://dx.doi. org/10.1016/j.catena.2005.11.001

BECKER, H. S. Métodos de pesquisa em ciências sociais. 4 ed. São Paulo: Hucitec, 1999, 178p.

BRIGGS, J. The use of indigenous knowledge in development: problems and challenges. Progress in Development Studies, v. 5, n. 2, p. 99-114, 2005. DOI: http://dx.doi.org/10.1191/1464993405ps105oa

CARDOSO, I. M. Percepção e uso, por pequenos agricultores, dos ambientes de uma microbacia no município de Ervália-MG. Viçosa, $M G$. 195p. Dissertação (Mestrado) - Universidade Federal de Viçosa, 1993.

CHAMBERS, $R$. The origins and practice of participatory rural appraisal. World Development, vol. $22 \mathrm{n} .7$, 953-969p, 1994. DOI: http://dx.doi.org/10.1016/0305750X(94)90141-4

CORREIA, J. R.; LIMA, A. C. S.; ANJOS, L. H. C. O trabalho do pedólogo e sua relação com comunidades rurais: observações com agricultores familiares no Norte de Minas Gerais. Cadernos de Ciência \& Tecnologia, Brasília, v. 21, n. 3, p. 447-467, 2004.

COSTA, J. B. A. Do tempo da fartura dos crioulos ao tempo de penúria dos morenos: a identidade através de um rito em Brejo dos Crioulos. 1999. 216p. Dissertação (Mestrado) - Universidade de Brasília, Brasília, DF.

DAYRELL, C. A. (Ed.). Diagnóstico de estratégias agroalimentares das comunidades quilombolas do
Gorutuba. Programa Biodiversidade Brasil Itália (relatório de pesquisa), 2006 (mimeo).

DAYRELL, C. A. Gerazeiros y biodiversidad em el Norte de Minas Gerais: lacontribuición de la agroecologia e de laetnoecologia em los estúdios de losagroecossistema. Huelva: Universidad Internacional de Andalúcia, 1998 (Dissertação de Mestrado).

DIEGUES, A. C. O Mito Moderno da Natureza intocada. São Paulo: Hucitec. 3 ed. 2000. 196 p.

EMBRAPA. Centro Nacional de Pesquisa de Solos. Manual de métodos de análise de solo. 2. ed. Rio de Janeiro, 1997. 212p. (EMBRAPA-CNPS. Documentos, 1).

EMBRAPA. Centro Nacional de Pesquisa de Solos. Procedimentos Normativos de Levantamentos Pedológicos. Brasília, DF: Embrapa-SPI. 1995. 101 p.

EMBRAPA. Centro Nacional de Pesquisa de Solos. Sistema Brasileiro de Classificação de Solos. 2. ed. Rio de Janeiro, 2006. 306 p.

ERNESTO SOBRINHO, F. et al. Sistema do pequeno agricultor do Seridó Norte Rio Grandense. A terra, o homem e o uso. Mossoró: Fundação Guimarães Duque, 1983. 200 p. (coleção Mossoroen-SE, 176).

GEILFUS, F. 80 herramientas para el desarrollo participativo: diagnóstico, planificacion, monitoreo $y$ evaluacion. Proyecto de cooperacíon IICA/GTZ: agricultura, recursos naturales y desarrollo sustenible. EDICPSA, San Salvador, El Salvador. 1997, 208 p.

GOBIN, A. et al. Integrated topossequence analyses to combine local and scientific knowledge systems. Geoderma, v. 97, p. 103-123, 2000. DOI: http://dx.doi. org/ 10.1016/S0016-7061(00)00029-X

GONÇALVES, C. W. P. As Minas e os Gerais - Breve ensaio sobre desenvolvimento e sustentabilidade a partir da Geografia do Norte de Minas. In: GUIMARÃES, P. W. et al. Cerrado e desenvolvimento: tradição e atualidade. Montes Claros: Unimontes. 2000, p. 19-45. 
GRAY, L. C.; MORANT, P. Reconciling indigenous knowledge with scientific assessment of soil fertility changes in southwetern Burkina Faso. Geoderma, v. 111, p. 425-437, 2003. DOI: http://dx.doi.org/10.1016/ S0016-7061(02)00275-6

GUZMÁN, E. S. A perspectiva sociológica em Agroecologia: uma sistematização de seus métodos e técnicas. Agroecologia e Desenvolvimento Rural Sustentável. Revista Emater/RS, v. 3, n. 1, 2002. p. 18-28.

JOHNSON, A. W. Ethnoecology and planting practices in a swidden agricultural system. Am. Ethnol. 1: 87-101. 1974.

KRASILNIKOV, P. V.; TABOR, J.A. Perspectives on utilitarian ethnopedology. Geoderma, v. 111, p. 197-215, 2003. DOI: http://dx.doi.org/10.1016/S00167061(02)00264-1

LANI, J. L. Estratificação de ambientes na bacia do rio Itapemirim no Sul do Estado do Espirito Santo. Dissertação (Mestrado), Universidade Federal de Viçosa, Viçosa 1987. 114p.

MARQUES, J. G. W. Pescando pescadores: ciência e etnociência em uma perspective ecológica. 2 ed. São Paulo, NUPAUB/Fundação Ford, 2001. 304p.

MENDONÇA, E. S.; MATOS, E. DA S. Matéria orgânica do solo: métodos de análises. Viçosa: UFV, 107 p. 2005.

MUNSELL. Soil color charts. Maryland, 1994.

RTID. Relatório técnico de identificação e delimitação da Comunidade Remanescente do Quilombo de Brejo dos Crioulos. Fundação Cultural Palmares: Rio de Janeiro. 2004. 79 p.

RESENDE, M. O manejo dos solos na agricultura sustentável. IN: Conferência Internacional - Tecnologia e Desenvolvimento Sustentável. Porto Alegre. 1995. 30p.

RESENDE, M. et al. Pedologia: base para distinção de ambientes. 4 ed. Viçosa: NEPUT, 2002. 338p.
RIST, S.; DAHDOUH-GUEBAS, F. Ethnosciences - a step towards the integration of scientific and indigenous forms of knowledge int the management of natural resources for the future. Environ Dev Sustain, v. 8, p. 467-493, 2006. DOI: http://dx.doi.org/10.1007/s10668006-9050-7

RUIZ, H. A. Dispersão fisica do solo para análise granulométrica por agitação lenta. In: CONGRESSO BRASILEIRO DE CIÊNCIA DO SOLO, 30., 2005, Recife - PE. CDROM. Sociedade Brasileira de Ciência do Solo, 2005a.

RUIZ, H. A. Incremento da exatidão da análise granulométrica do solo por meio da coleta da suspensão (silte + argila). R. Bras. Ci. Solo, v.29, p.297-300, 2005b. DOI: http://dx.do.org/10.1590/S0100-06832005000200015

SANTOS, R. D. DOS et al. Manual de descrição e coleta de solo no campo. 5 ed. Revista e ampliada. Viçosa: Sociedade Brasileira de Ciência de Solo, 2005. 100p.

TABOR, J. A. Ethnopedology surveys: soil surveys that incorporate local systems of land classification. Soil Sur. Horiz., 33:1-5. 1992.

TOLEDO, V. M.; ALARCÓN-CHÁIRES, P.; BARÓN, L. Estudiarlo rural desde uma perspectiva interdisciplinaria: una aproximacíonal caso de México. Estudios Agrarios, 12:55-90. 1999.

TOLEDO, V.M. La apropriacion Campesina de La Naturaleza: um análisis etnoecologico. México. 1996. (mimeo).

WINKLERPRINS, A.M.G.A.; BARRERA-BASSOLS, N. Latin American ethnopedology: a vision of its past, present, and future. Agriculture and Human Values, v. 21, p. 139-156, 2004. DOI: http://dx.doi.org/10.1023/ B:AHUM.0000029405.37237.c8

YEOMANS, J.C.; BREMNER, J.M. A rapid and precise method for routine determimation of organic carbon in soil. Commun. Soil Science Plant Anal., v. 19, p. 1467-1476, 1988. DOI: http://dx.doi. org/10.1080/00103628809368027 